\title{
Composition Effect on Some Physical Properties and FTIR Spectra of Alumino - Borate Glasses Containing Lithium, Sodium, Potassium and Barium Oxides
}

\author{
H. A. Silim \\ Glass Research Group (GRG), Physics Department, Faculty of Science, \\ Mansoura University, Mansoura POB 35516, EGYPT.
}

The composition effect on FTIR spectra, D. C. electrical conductivity, density and molar volume have been carried out for five glasses (G1 to G5) of (13 $\mathrm{M}_{2} \mathrm{O}$ or $\left.\mathrm{M}^{\prime} \mathrm{O}\right)-78 \mathrm{~B}_{2} \mathrm{O}_{3}-x \mathrm{Al}_{2} \mathrm{O}_{3}-y$ Nacl system, where $\mathrm{M}$ is $\mathrm{Li}$, Na or $\mathrm{K}$ and $M^{\prime}$ is $B a ; x=9$ and $y=0$ for G1, while for G2, G3, G4 and G5: $x=3$ and $y=6 \mathrm{~mol} \%$. FTIR spectra have been recorded in wavenumber range from $4000 \mathrm{~cm}^{-1}$ to $400 \mathrm{~cm}^{-1}$. Eight absorption bands were observed in the rgion from $400-1750 \mathrm{~cm}^{-1}$. The electrical conductivity yield activation energies for the investigated glasses. These activation energies as well as the density and the molar volume have been found to be in the fallowing order $\mathrm{Li}^{+}<\mathrm{Na}^{+}<\mathrm{K}$. The molar volume, density and the activation energy for barium oxide seem to be constant whether $\mathrm{Na} \mathrm{Cl}$ is present or not.

\section{Introduction}

\subsection{Some remarks on the glass structure:}

Chemical composition of the glasses plays an important role in determining properties of the glass. The glass is divide into main categories: network formers, network modifiers and intermediate species, which falls somewhere between network formers and modifiers and may substitute for a network former in the glassy state. Higher valence cations such as $\mathrm{Al}^{3+}$ are commonly used as intermediate species [1]. In the present study the influence of the network modifier ( $\mathrm{Li}, \mathrm{Na}, \mathrm{K}$ and $\mathrm{Ba}$ ) was determined from the experimental properties of the alumino - borate system.

e-mail: hasilim@hotmail.com 
Infrared spectroscopy has been proven to be a useful tool for investigating the structure and dynamics of amorphous solids $[2$ and ref. therein]. The structure of glasses with composition $\mathrm{xB}_{2} \mathrm{O}_{3}-(1-\mathrm{x}) \mathrm{M}_{2} \mathrm{O},(\mathrm{M}=\mathrm{Li}$, $\mathrm{Na}, \mathrm{K}, \mathrm{Rb}, \mathrm{Cs}$ ) is known to be consist of $\mathrm{B}-\mathrm{O}$ network, built up from planner three- coordinated and tetrahedral four coordinated boron atoms [2], figure (1a). Pure $\mathrm{v}-\mathrm{B}_{2} \mathrm{O}_{3}$ contains only three coordinated boron atoms $\left[\mathrm{BO}_{3}\right]^{3-}$ and if an alkali oxide $\left(\mathrm{M}_{2} \mathrm{O}\right)$ is added some of these units transform into four coordinated tetrahedral [3] as shown in Fig. (1-b).

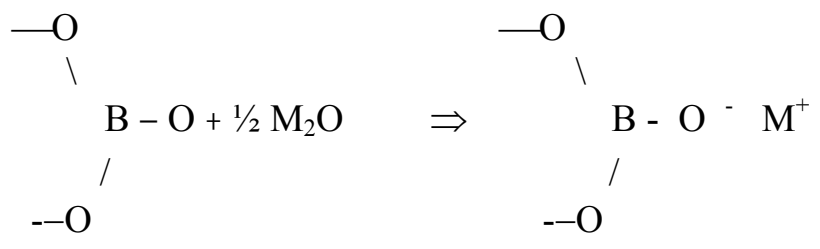

Fig. (1-a): Formation of non-bridging oxygen [4] from addition of an alkali oxide $\left(\mathrm{M}_{2} \mathrm{O}\right)$.

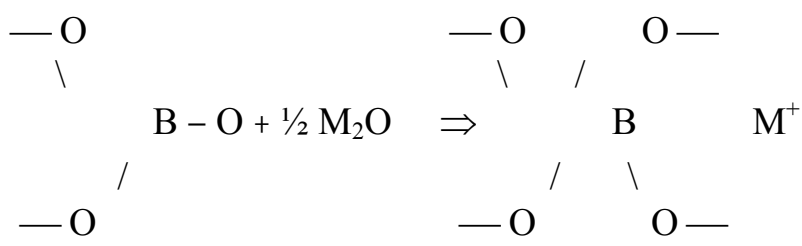

Fig. (1-b): The conversion of boron from a 3-coordinated state to a 4- coordinated state [4] as a result of the addition an alkali oxide $\mathrm{M} 2 \mathrm{O}$.

If an alkali impurity creates non-bridging, Fig.(1-a); the resulting network gets loose and the connectivity of $\mathrm{B}_{2} \mathrm{O}_{3}$ network decreases. This leads the glass properties such as thermal coefficient expansion, electrical conductivity and so on, all increase with increasing modifier content. If an alkali impurity causes boron atom to be tetrahedral, Fig (1- b), the connectivity increases followed by decreasing in the glass properties. The structure role of the network modifier is determined by its size and charge and by network forming agent of the glass.

In the present work four modifiers, $\mathrm{Ba}^{2+}, \mathrm{K}^{+}, \mathrm{Na}^{+}$, and $\mathrm{Li}^{+}$have been used with the mol \% in the glasses under investigation. In barium and lead alumino-borate glasses, it was reported that aluminum atoms have mainly a tetrahedral coordination with respect to oxygen [5]. In the glass system of $\mathrm{BaO}$ $-\mathrm{Al}_{2} \mathrm{O}_{3}-\mathrm{B}_{2} \mathrm{O}_{3}$, it was assumed that aluminum ion enter the glass structure in the form of triclusters which consisted of three tetrahedral $\mathrm{BO}_{4}$ and / or $\mathrm{Al}_{2} \mathrm{O}_{3}$ in 
the form of $\mathrm{AlO}_{4}$ having oxygen in common [6-8]. Owen [8] proposed, for the glass systems of $\mathrm{MO}-\mathrm{AL}_{2} \mathrm{O}_{3}-\mathrm{B}_{2} \mathrm{O}_{3}(\mathrm{M}=\mathrm{SR}$, $\mathrm{Ca}$ and $\mathrm{Ba})$, that some of $\mathrm{M}$ associate itself with $\mathrm{Al}_{2} \mathrm{O}_{3}$ forming $\mathrm{AlO}_{4}$ and the rest act with $\mathrm{B}_{2} \mathrm{O}_{3}$ producing $\mathrm{BO}_{4}$ or non- bridging oxygen ions. Sakae [9] concluded that the ratio $\mathrm{Al}_{2} \mathrm{O}_{3}$ / $\mathrm{CaO}$ has the same effect on the glass structure where $\mathrm{ALO}_{4}$ dependent on $\mathrm{B}_{2} \mathrm{O}_{3}$. Prince [10] reported that the glass stability increases with respect to the devitrfication process when $\mathrm{Al}$ acting as a glass former in the $\mathrm{BaO}-\mathrm{Al}_{2} \mathrm{O}_{3}-$ $\mathrm{B}_{2} \mathrm{O}_{3}$ system.

The aim of the present work is to study the influence of the glass composition on some physical properties and the IR spectra of the glasses under investigation.

\section{Experimental:}

\subsection{Preparation of the glass samples}

The investigated glasses have been prepared by mixing appropriate quantities from the reagent materials. These raw materials are barium carbonate, orthoboric acid, aluminum oxide, sodium chloride, lithium oxide, sodium oxide and potassium oxide. The required mixture from these reagents was melt in air in porcelain crucibles in an electric furnace.

The homogenized melts were cast into stainless steel moulds and subsequently cooled down to room temperature. Transparent glasses were obtained and its amorphous nature was confirmed by X-ray diffraction. The compositions of the studied glasses are given in Table (1).

Table (1): The compositions of the studied glasses in mole \%.

\begin{tabular}{||c||c|c|c|c|c||}
\hline & $\mathrm{G} 1$ & $\mathrm{G} 2$ & $\mathrm{G} 3$ & $\mathrm{G} 4$ & $\mathrm{G} 5$ \\
\hline \hline $\mathrm{BaO}$ & 13 & - & - & - & - \\
\hline $\mathrm{BaO}$ & - & 13 & - & - & - \\
\hline $\mathrm{Li}{ }_{2} \mathrm{O}$ & - & - & 13 & - & - \\
\hline $\mathrm{Na}_{2} \mathrm{O}$ & - & - & - & 13 & - \\
\hline $\mathrm{K}_{2} \mathrm{O}$ & - & - & - & - & 13 \\
\hline $\mathrm{B}_{2} \mathrm{O}_{3}$ & 78 & 78 & 78 & 78 & 78 \\
\hline $\mathrm{Al}_{2} \mathrm{O}_{3}$ & 9 & 3 & 3 & 3 & 3 \\
\hline $\mathrm{Nacl}^{2}$ & - & 6 & 6 & 6 & 6 \\
\hline
\end{tabular}




\subsection{D.C. Electrical Conductivity Measurements}

The resistances of three samples from each glass under investigation have been carried out using an Insulator Tester Type TM14 with $10^{3}-10^{13} \mathrm{ohm}$ range. The thickness of each sample is $(1-2 \mathrm{~mm})$.

The glass surfaces were coated with silver paste to serve as electrodes. The resistivity of each sample has been calculated and the relation between $\ln \rho$ and $10^{3} / \mathrm{T}\left(\mathrm{K}^{-1}\right)$ for the investigated glasses are shown in Fig. (2).

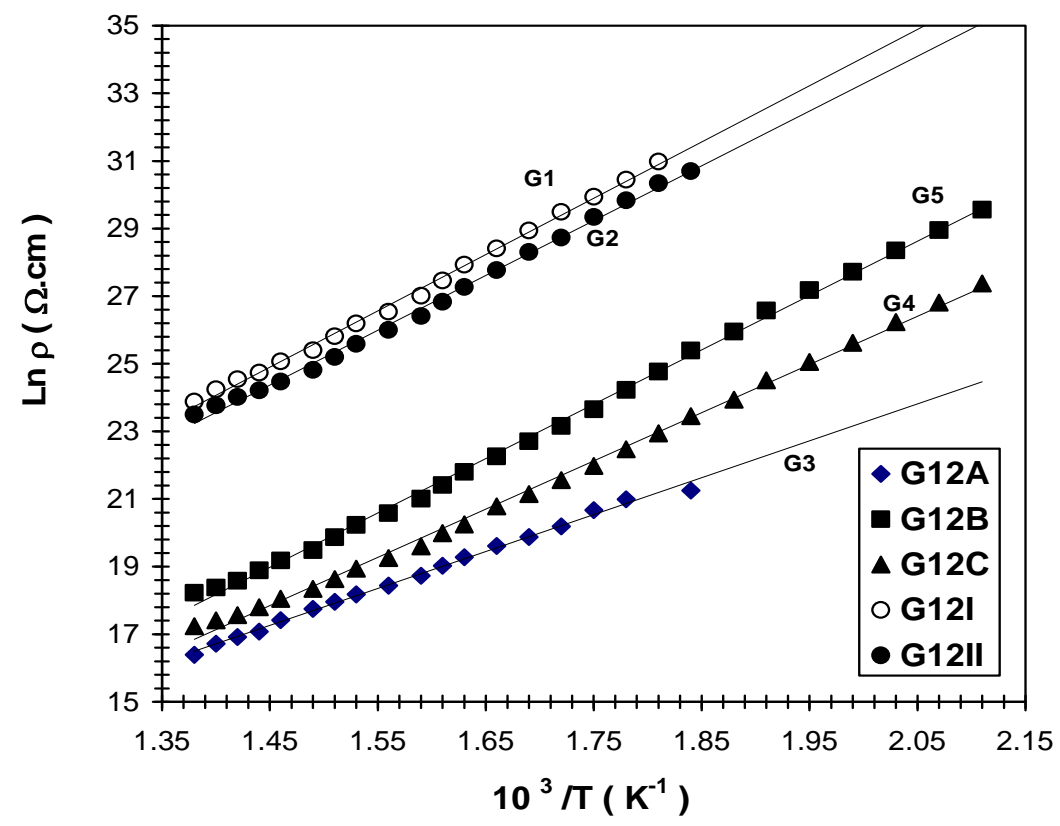

Fig. (2): Change of the natural logarithm of electric resistivity for the investigated glasses with temperature.

\subsection{Infrared Spectroscopy}

FTIR absorption spectra of the glasses under investigation have been recorded in the wavenumber range $4000-400 \mathrm{~cm}^{-1}$ using Mattson 5000 system. $10 \mathrm{mg}$ of each sample was mixed with $1000 \mathrm{mg}$ of $\mathrm{KBr}$ in an agate mortar and then pressed into pellets of $13 \mathrm{~mm}$ diameter. The spectrum of each sample represents an average of 20 scans, which were normalized to the spectrum of the blank $\mathrm{KBr}$ pellet. A spectral resolution of $2 \mathrm{~cm}^{-1}$ was chosen and the spectrum has been carried for three samples from each glass to avoid any errors during the measurements. 


\subsection{Density and Molar Volume}

The density measurements for the studied glass were carried out at room temperature using Archimedes method with xylene as immersion fluid. The measurements were carried out for three samples from each glass. The relative error in these measurements was about $\pm 0.03 \mathrm{~g} \mathrm{~cm}^{-3}$ and the molar volume $\mathrm{Vm}$ was calculated from the molecular weight $\mathrm{M}$ and the density $\rho$ according to the relation: $\mathrm{V}_{\mathrm{m}}=\mathrm{M} / \rho$

\section{Results and Discussion}

\subsection{D.C. Electrical Conductivity}

The electrical conductivity of the investigated glasses was measured as a function of temperature (from $470-730 \mathrm{~K}$ for the investigated glass) and found to fulfils the following Arhenius formula:

and the resistivity

$$
\sigma=\sigma_{\mathrm{o}} \mathrm{e}^{-\mathrm{E} / \mathrm{KT}}
$$

$$
\rho=\rho_{\mathrm{o}} \mathrm{e}^{\mathrm{E} / \mathrm{KT}}
$$

where E represents the activation energy for the electronic conduction, $\rho_{\mathrm{o}}$ is the pre-exponential factor contains several constants including the viberational frequency of the mobile ions [20,21] and is given by:

$$
\rho_{\mathrm{o}}=2 \mathrm{KT} / \mathrm{N} \mathrm{q}^{2} \mathrm{a}^{2} \mathrm{f}
$$

The relation between $(\ln \rho)$ and $10^{3} / \mathrm{T}\left(\mathrm{K}^{-1}\right)$ is given in figure (2). It is obvious, from this figure, that $(\ln \rho)$ increases in the order $\mathrm{Li}^{+}<\mathrm{Na}^{+}<\mathrm{K}^{+}<$ $\mathrm{Ba}^{++}$. This means that the conductivity of the investigated glasses depends completely on the size and charge of the network modifiers in the glass. The calculated values of the activation energies are given in Table (2) and found to be inconsistent with the expected values.

Table (2): The calculated values for the activation energy, density and molar volume for the glasses under investigation

\begin{tabular}{|c||c|c|c||}
\hline \hline & $\begin{array}{c}\text { Activation energy, E } \\
(\mathrm{ev})\end{array}$ & $\begin{array}{c}\text { Density, } \\
\left(\mathrm{gm}^{-3} \mathrm{~cm}^{-3}\right)\end{array}$ & $\begin{array}{c}\text { Molar volume, } \mathrm{V}_{\mathrm{m}} \\
\left(\mathrm{cm}^{3}\right)\end{array}$ \\
\hline G1 & 1.4440 & 2.001 & 47.92 \\
\hline G2 & 1.3999 & 2.004 & 46.55 \\
\hline G3 & 0.9431 & 1.885 & 40.98 \\
\hline G4 & 1,2317 & 1.708 & 47.66 \\
\hline G5 & 1.3893 & 1.658 & 51.63 \\
\hline
\end{tabular}




\subsection{Analysis of FTIR spectra}

Infrared spectroscopy is known to provide insights into the interaction between alkali metal ions and borate glass network. Absorption of these borate glasses is very high in the region of interest of wave numbers $<2000 \mathrm{~cm}^{-1}$. The FTIR spectra were recorded in the wavenumber region $2000-400 \mathrm{~cm}^{-1}$. The spectra can be divided into the following regions: (1) $600-800 \mathrm{~cm}^{-1}$ is related to the bending vibrations of various borate arrangements $\mathrm{B}-\mathrm{O}-\mathrm{B}$, (2) $800-$ $1200 \mathrm{~cm}^{-1}$ was attributed to the $\mathrm{B}-\mathrm{O}$ stretching vibrations of tetrahedral $\left[\mathrm{BO}_{4}\right]$ and (3) $1200-1800 \mathrm{~cm}^{-1}$, the peaks in this region were related to $\mathrm{B}-\mathrm{O}$ stretching vibrations of $\left[\mathrm{BO}_{3}\right]$. The bands in three active regions of the spectra are similar to those reported on alkali borate 11-13] and barium aluminoborate glasses $[5,12]$. In the forth absorption region $\left(400-600 \mathrm{~cm}^{-1}\right)$, where the sixfold coordination of aluminum atoms can be detected $[5,10]$ the bands appeared in this region is due to $\mathrm{Al}-\mathrm{O}$ stretching vibration in the $\left(\mathrm{AlO}_{6}\right)$ groups.

Figures (3-5) represent the deconvolution spectra for the glass containing lithium oxide (G3) and barium oxide (G2 and G1). The FTIR absorption spectra of the investigated glasses have analyzed in more details using the Gaussian bands and the computer PeakFit program [19]. It is obvious from these figures that broad bands were observed and centered at $464 \mathrm{~cm}^{-1}$ for $\mathrm{G} 3$ and at about $435 \mathrm{~cm}^{-1}$ for G1. These bands have attributed to the vibration of cations of lithium and barium atoms at their network sits [14]. In some cases it was referred to the formation of units combined with the network [22 \&23].

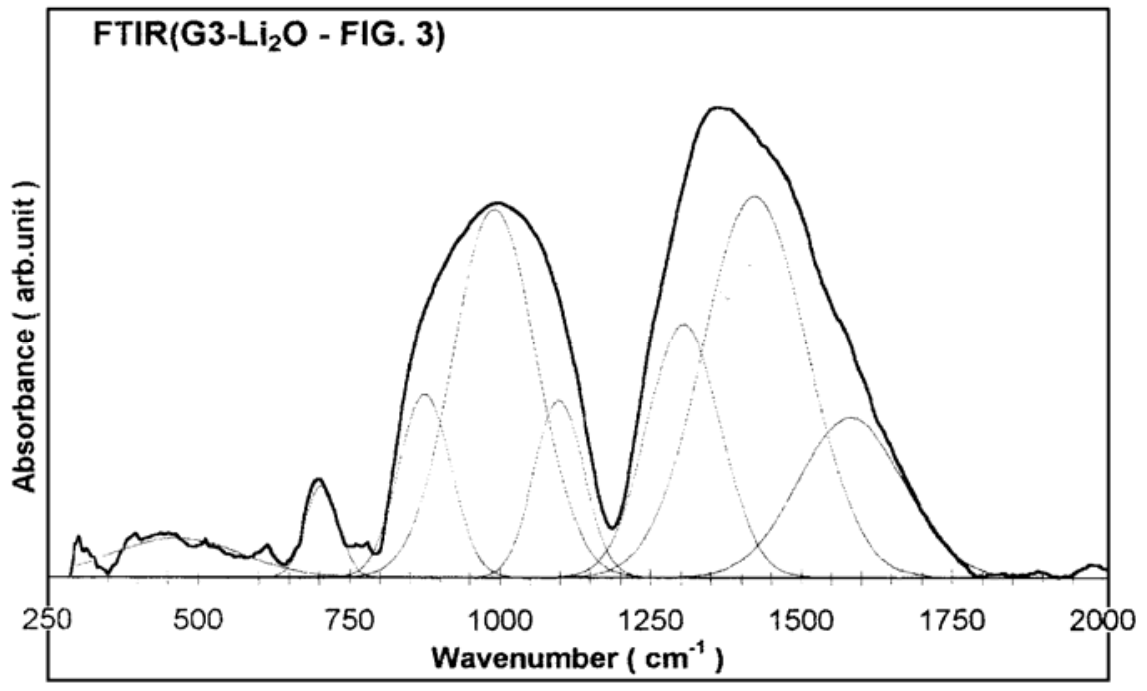

Fig. (3): Deconvolution result for $13 \mathrm{Li}_{2} \mathrm{O}-3 \mathrm{Al}_{2} \mathrm{O}_{3}-78 \mathrm{~B}_{2} \mathrm{O}_{3}-6 \mathrm{Nacl}$, experimental absorption spectrum (solid line) and computer band (dashed lines), [G3]. 


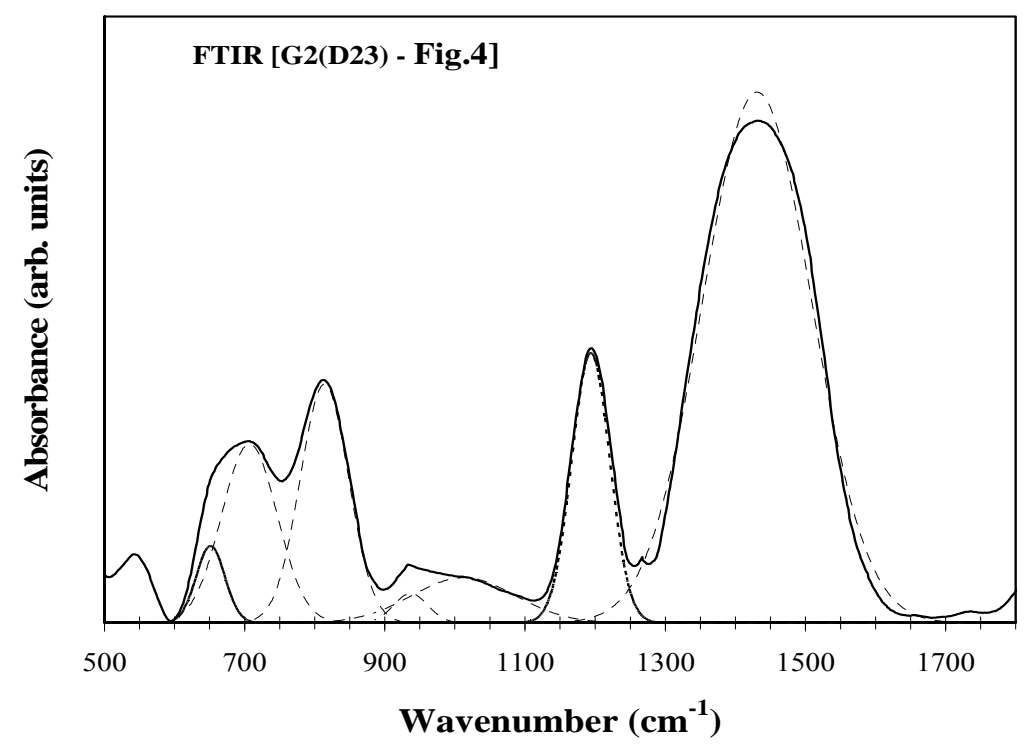

Fig. (4): Deconvolution result for $13 \mathrm{BaO}-3 \mathrm{Al}_{2} \mathrm{O}_{3}-78 \mathrm{~B}_{2} \mathrm{O}_{3} 6 \mathrm{Nacl}$, experimental absorption spectrum (solid line) and computer band (dashed lines), [G2].

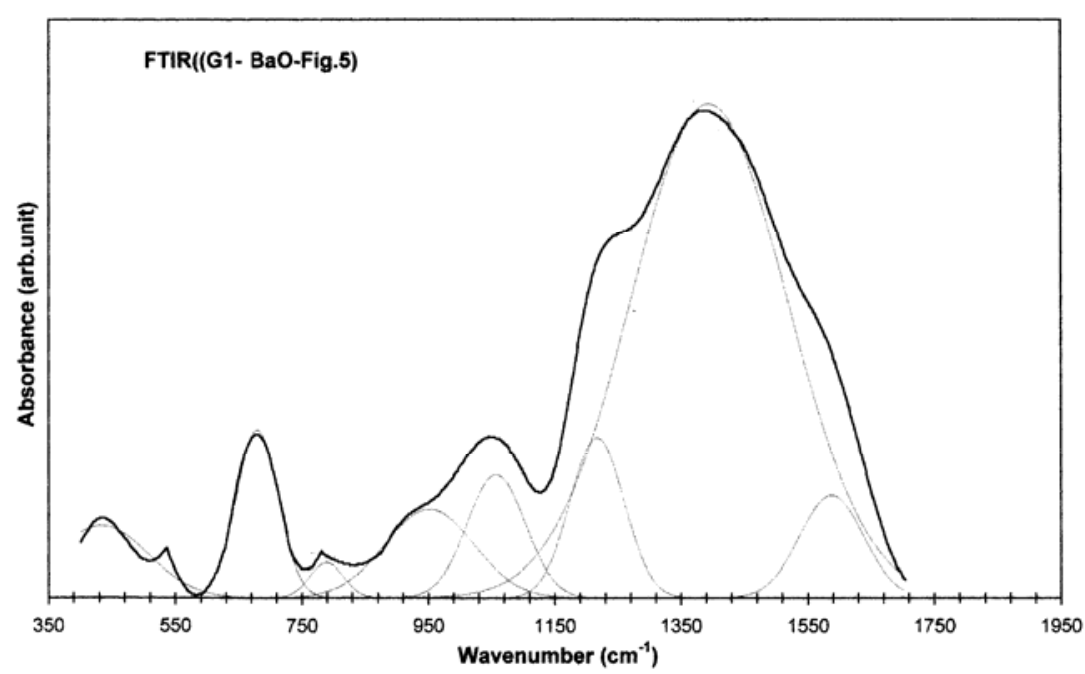

Fig. (5): Deconvolution result for $13 \mathrm{BaO}-9 \mathrm{Al}_{2} \mathrm{O}_{3}-78 \mathrm{~B}_{2} \mathrm{O}_{3}$, experimental absorption spectrum (solid line) and computer band (dashed lines), [G1].

We assign the intense bands centered at 1001 and $1427 \mathrm{~cm}^{-1}$ in the regions $800-1200-1700 \mathrm{~cm}^{-1}$ for $\mathrm{G} 3$ to the vibration of boron atoms with respect to the four oxygen atoms surrounding it. 
The remaining peaks were attributed to $\mathrm{B}-\mathrm{O}-\mathrm{B}$ stretching vibrations associated with $\mathrm{BO}_{4}$ tetrahedral which are connected to the other network unit. The four peaks in the spectral region $600-800 \mathrm{~cm}^{-1}$ were appeared at 610,686 , 703 and $772 \mathrm{~cm}^{-1}$ and assigned to the bending vibration of borate segments [12-14].

In the barium aluminoborate glass (G1), Fig (5), the absorption peaks in the region $400-600 \mathrm{~cm}^{-1}$ were at $600 \mathrm{~cm}^{-1}$ or less were assigned to the vibration of the modifier cations with respect to barium atoms. The more intense peaks in the region $600-800 \mathrm{~cm}^{-1}$ are at $679 \mathrm{~cm}^{-1}$ where the tetrahedral $\mathrm{BO}_{4}$ is obvious and the other peaks are related to the boroxol $\left[\mathrm{BO}_{3}\right]$ units. In the absorption band at $952 \mathrm{~cm}^{-1}$ is due to diborate network. The other peaks are due to the formation of pentaborate and that at $1395 \mathrm{~cm}^{-1}$; the intensive peaks; are assigned to the metaborate chain [12] where $\mathrm{BO}_{4}$ units are formed on the expense of $\mathrm{BO}_{3}$ with non-bridging oxygen atoms. The peak at $1587 \mathrm{~cm}^{-1}$ is raised from $\mathrm{B}-\mathrm{O}$ stretching vibration of triangle [BO3 $]^{-3}$ units $[11,12,16$ and 17].

Each spectrum for all alkali atoms ( $\mathrm{Li}, \mathrm{Na}$ and $\mathrm{K}$ )- aluminoborate glasses contains the number of bands at approximately the same wavenumbers but may be with different intensities and widths. Therefore, one may conclude that, for example, the large potassium atoms open up the network and force $\mathrm{BO}_{4}$ units to interconnect with the narrower distribution of $\mathrm{B}-\mathrm{O}-\mathrm{B}$, resulting in the IR spectrum with narrower peaks.

\subsection{Density (D) and Molar Volume (Vm)}

The dependence of density, molar volume and activation energies on the glass compositions were given in Table (2). A slightly decrease in $\mathrm{D}, \mathrm{m}_{\mathrm{V}}$ and $\mathrm{E}$ were noticed from $\mathrm{G} 1$ up to G3, while a significant increase was observed in both $V_{m}$ and $E$ from G3 to G5.The Nacl contents has no effect on these physical properties of the studied glasses of barium alumino- borate.

\section{Conclusions:}

The conductivity of the studied glasses depends completely on the size and charge of the cations of the mole $\%$ content. The activation energies were found to be constant for $\mathrm{BaO}$ with or without $\mathrm{Nacl}$ while that of the alkaline oxides increases as $\mathrm{K}^{+}>\mathrm{Na}^{+}>\mathrm{Li}^{+}$. The density, molar volume and the activation energies were found to be constant for G1 and G2. This means that Nacl contents has no effect on these physical properties of the present glasses containing $\mathrm{BaO}$, while for that containing $\mathrm{Li}_{2} \mathrm{O}, \mathrm{Na}_{2} \mathrm{O}$ and $\mathrm{K}_{2} \mathrm{O}$ it was found that $\mathrm{E}$ and $\mathrm{V}_{\mathrm{m}}$ increased from $\mathrm{G} 3$ to $\mathrm{G} 5$ and $\mathrm{D}$ decreases.

The FTIR spectra of the alkaline oxides ( $\mathrm{Li}, \mathrm{Na}, \mathrm{K}$ ) aluminoborate glasses have been found to have the equal number of peaks at approximately the 
same wavenumbers. In barium aluminoborate glasses with or without Nacl the peaks in the regions $400-600 \mathrm{~cm}^{-1} 600-800 \mathrm{~cm}^{-1}$ and at $793 \mathrm{~cm}^{-1}$ are assigned to the vibration of the cations in the network, to the boroxol $\left[\mathrm{BO}_{3}\right]$ and the formation of $\left[\mathrm{BO}_{4}\right]$, respectively. Peaks in the region $800-1200 \mathrm{~cm}^{-1}$ are due to diborate, pentaborate and the more intense one is assigned to metaborate. Two peaks observed at the region $1200-1750 \mathrm{~cm}^{-1}$ are due to pentaborate, one arise from $\mathrm{B}-\mathrm{O}$ stretching vibration of $\left[\mathrm{BO}_{3}\right]^{3-}$ and the intense one is due to the metaborate chain.

\section{References:}

1. J. Mauro, Report from: Glass Laboratory, College of Ceramics, Alfred University. Private communication through the Internet (2000).

2. J.Wong and C. A. Angell, "Glass Structure by Spectroscopy", Dekker, New York (1976).

3. D. L. Griscon, "Borate Glasses, Structure, Application”, Ed: I. D. Pye, V. D. Frechette and N. J. Kreidl (Plenum, New York, 1978).

4. A. K. Varshneya, "Fundamentals of Inorganic Glasses", San Diego: Academic Press, Inc. (1994).

5. V. Z. Kreitsberga, V. G. Chekhovskii, A. P. Sizonenko, Yu. Ya. Keishs, S. E. Redala and P. G. Pauksh, Fiz. Khim Stekla 17, 953 (1991).

6. H.Scholze, "Glass; Nature, Structure and Properties", Springer, New York (1991).

7. J. E. Shelby, "Introduction to Glass Science and Technology", The Royal Society of Chemistry, Combridge (1997).

8. A. E. Owen, Phys. Chem. Glasses 2, 152 (1961)

9. S. Sakka, Yogyo- Kyokai- Shi 85299 (1977).

10. P. Perince, S. Esposito, A. Aronne and V. N. Sigaev, J. Non-Cryst. Solids 258, 1 (1999).

11. Krogh Moe, Phys. Chem. Glasses 6, 46 (1965).

12. E. I. Kamitsos, M. A. Karakassides and G. D. Chyrssikos, J.Phys. Glasses 91, 1073 (1987).

13. E. I. Kamitsos, A. P. Patsis, M. A. Karakassides and G.D. Chyrssikos, J. Non-Cryst. Solids 126, 52 (1990).

14. H. A. Silim, accepted for publication in: Egyptian Journal of Solids, (2002).

15. P. Perince, S. Esposits and A. Arone, Phys. Chem. Glasses 39, 222 (1998).

16. P. Perince, A. Arone and A. Marrotta, Mater. Chem. Phys. 30, 195 (1992).

17. P. Perince, A. Arone and M. Cataura, Phys. Chem. Glasses 37, 134 (1996).

18. A. H. Verhoef and H. W. den Hatog, J. Non- Cryst. Solid 182, 221 (1995).

19. Jandel Scientific PeakFit, Copyright $(C)$ AISN Software (1990).

20. A. R. West, Solid State Chemistry and its Application, Wiley, 455 (1984). 
21. F. Branda, P. Prince, A. Arone, C.Cstantini and A. Buri, Phys. Chem. Glasses 31(2) 75 (1990).

22. M. J. Weber, J. Non-Cryst. Solids 123, 208 (1990).

23. C. A. Hogarth and M. N. Khan, J.Non-Cryst. Solids 123, 339 (1990). 